\title{
Stress in farmers: a survey of farmers in England and Wales
}

\author{
Sue Simkin, Keith Hawton, Joan Fagg, Aslög Malmberg
}

\begin{abstract}
Objectives-To investigate potential sources of stress for farmers in England and Wales

Method-A postal questionnaire was sent to a randomly selected group of $800 \mathrm{mem}$ bers of the National Farmers' Union and 200 members of the Farmers' Union of Wales.

Results-500 questionnaires (51\%) were returned completed between October 1995 and March 1996. Farmers had problems with record keeping and paperwork $(62 \%)$, difficulty understanding forms (56\%), and problems arising from the effects of new legislation and regulations (49\%). Nearly a quarter $(23 \%)$ reported financial problems and most worried about money $(79 \%)$. Very few were socially isolated, with over $90 \%$ having at least one confidant. $70 \%$ worked $>10$ hours a day, and $31 \%$ had health problems which interfered with their work, including more than a quarter of those $<50.16 \%$ of the sheep farmers reported symptoms which they attributed to organophosphate poisoning. The farmers most vulnerable to financial and other problems were those with small farms and mixed farming operations. Farmers in Wales also seemed more vulnerable than those in England, but a lower response rate from members of the Farmers' Union of Wales means this difference should be interpreted cautiously.

Conclusion-The survey confirms findings from several regional studies that many farmers are experiencing considerable stress from various causes. Local and national initiatives to assist farmers, including outreach programmes, should be encouraged. Policy makers should be aware of the potential impact of legislation, particularly on the more vulnerable groups.

(Occup Environ Med 1998;55:729-734)
\end{abstract}

Keywords: farmers; stress; postal questionnaire

Psychiatry, Warneford

Hospital, Headington, Oxford, UK

S Simkin

K Hawton

J Fagg

A Malmberg

Correspondence to:

Professor Hawton, University

of Oxford, Department of

Psychiatry, Warneford

Hospital, Headington,

Oxford OX2 7JX, UK

Accepted 26 June 1998

In recent years there has been growing concern about levels of stress being faced by farming communities. $^{1-4}$ This has been particularly highlighted by evidence of increased risk of suicide in farmers in England and Wales. ${ }^{5}$

To explore the main problems faced by farmers, and to identify which farmers were most vulnerable to possible causes of stress, we conducted a postal questionnaire survey of farmers in England and Wales. The content of the survey was based on consultation with the National Farmers' Union (NFU) and a literature review. The factors were based on a stress vulnerability model in which it was hypothesised that certain factors were likely to be particularly stressful and frequent (financial problems, difficulties with new legislation and regulations, health problems) and that others would increase vulnerability to stress (number of confidants, social isolation). In the light of recent concerns about possible mental health consequences of organophosphate toxicity we also included questions about exposure to organophosphate compounds. To detect other problems, respondents were invited to add their own comments on causes of stress in farmers. They were also asked to suggest ways to alleviate stress. The survey took place between October 1995 and March 1996.

\section{Method}

A pilot study was carried out with 19 local NFU members. After revision the questionnaire (appendix, to be completed by farm owners and farm managers) was sent to 800 randomly selected members of the NFU, and 200 randomly selected members of the Farmers' Union of Wales (FUW). The NFU members who had not returned the questionnaire within a month were sent a further copy. The NFU has about 70000 full time farming members and 13000 retired members, covering on average $75 \%$ of English acreage ( $80 \%$ in the south west) and $50 \%$ of Welsh acreage. The FUW represents about 15000 Welsh farmers. Postcodes were used to allocate farmers to counties and geographical regions as defined by the Ministry of Agriculture, Fisheries, and Food (MAFF). ${ }^{6}$

\section{STATISTICAL ANALYSIS}

Statistical analyses were conducted with SPSS 6.1.1 for Windows, and included $\chi^{2}$, relative risk with $95 \%$ confidence interval $(95 \% \mathrm{CI})$, and Spearman's rank correlation coefficient. The numbers of respondents varied for each question. Therefore the numerators and denominators are shown where less than the total sample responded to a question.

\section{Results}

\section{RESPONDENTS}

Completed questionnaires were returned by 445 NFU members and 55 FUW members. A further 24 questionnaires were returned uncompleted by NFU members who were no longer in farming. Thus, omitting those farmers who had left farming, completed questionnaires were returned by $445 / 776$ (57\%) 
Table 1 Farm type

\begin{tabular}{|c|c|c|c|c|c|c|c|c|}
\hline & Arable & Dairy & Beef & Sheep & Pigs & Poultry & Horticulture & Other \\
\hline \multicolumn{9}{|c|}{ England $(n=384)$ : } \\
\hline $\mathrm{n}$ & 212 & 122 & 171 & 130 & 32 & 30 & 37 & 34 \\
\hline$\%$ & 55.2 & 31.8 & 44.5 & 33.9 & 8.3 & 7.8 & 9.6 & 8.9 \\
\hline \multicolumn{9}{|c|}{ Wales $(n=113)$ : } \\
\hline $\mathrm{n}$ & 15 & 45 & 92 & 84 & 4 & 6 & 4 & 10 \\
\hline$\%$ & 13.3 & 39.8 & 81.4 & 74.3 & 3.5 & 5.3 & 3.5 & 8.8 \\
\hline \multicolumn{9}{|c|}{ All respondents $(n=500)$ : } \\
\hline $\mathrm{n}$ & 229 & 167 & 266 & 217 & 36 & 37 & 41 & 44 \\
\hline$\%$ & 45.8 & 33.4 & 53.2 & 43.4 & 7.2 & 7.4 & 8.2 & 8.8 \\
\hline
\end{tabular}

^Individual people could have more than one farm type.

NFU members (384/676 (57\%) from England, $58 / 97(60 \%)$, from Wales (three addresses not known)) and 55/200 (28\%) FUW members, an overall response rate of 500/976 (51\%). Also, 393 farmers added comments to the questionnaire. We were able to identify a postcode for all but three of the NFU members (who have therefore been included in the overall figures but excluded from regional comparisons).

The geographical distribution of the NFU members who returned the questionnaire was similar to that of non-returners. Three hundred and eighty four farmers lived in England, 113 in Wales. There was a high correlation between the distribution of the respondents within the MAFF regions of England and the counties of Wales and the geographical distribution of farmers, partners, and directors reported in the Digest of Agricultural Census Statistics ${ }^{6}$ (for English regions Spearman's $r=0.98, \mathrm{p}<0.0001$; for Welsh counties Spearman's $r=0.93, \mathrm{p}<0.001$ ).

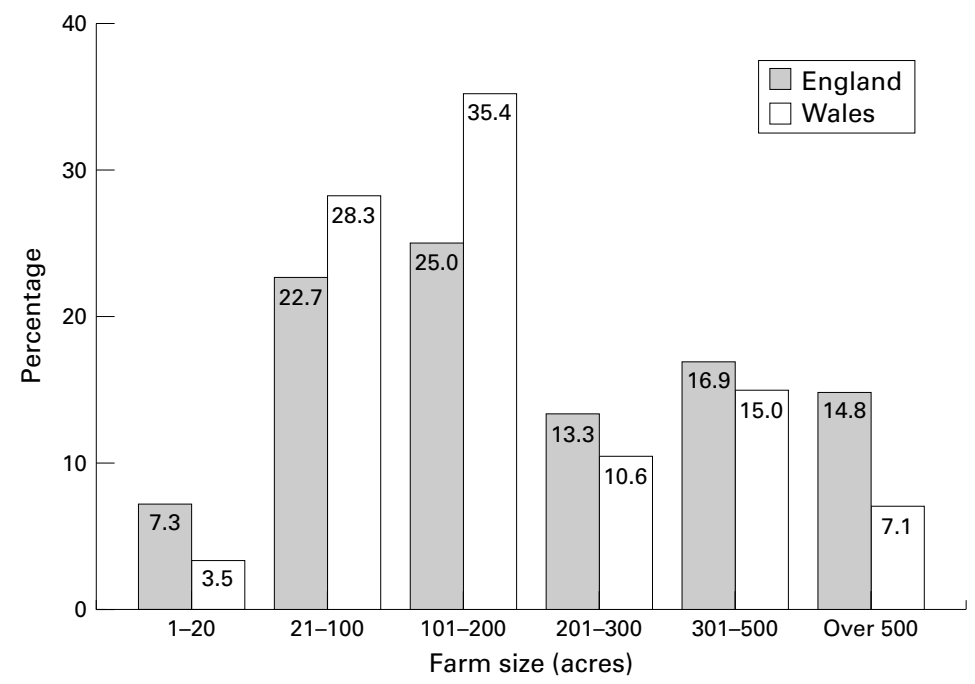

Figure 1 Farm size of respondents from England and from Wales (actual percentages shown within the columns).

Table 2 Financial problems reported by farmers in England and Wales

\begin{tabular}{|c|c|c|c|c|c|c|}
\hline & \multirow{2}{*}{$\begin{array}{l}\text { Financial } \\
\text { problems } \\
(n=494)\end{array}$} & \multicolumn{2}{|c|}{$\begin{array}{l}\text { Worried about money } \\
(n=496)\end{array}$} & \multicolumn{3}{|c|}{$\begin{array}{l}\text { Financial situation affected by } \\
\text { changes in legislation/regulations } \\
(n=483)\end{array}$} \\
\hline & & $\begin{array}{l}\text { Some of the } \\
\text { time }\end{array}$ & $\begin{array}{l}\text { Most of the } \\
\text { time }\end{array}$ & Worse & $\begin{array}{l}\text { No } \\
\text { change }\end{array}$ & Better \\
\hline \multicolumn{7}{|c|}{ England $(n=384)$} \\
\hline $\mathrm{n}$ & 80 & 265 & 44 & 93 & 158 & 120 \\
\hline$\%$ & 21.0 & 69.2 & 11.5 & 25.1 & 42.6 & 32.3 \\
\hline \multicolumn{7}{|c|}{ Wales $(n=113)$} \\
\hline $\mathrm{n}$ & 31 & 60 & 21 & 36 & 56 & 20 \\
\hline$\%$ & 27.4 & 53.1 & 18.6 & 32.1 & 50.0 & 17.9 \\
\hline
\end{tabular}

DEMOGRAPHIC CHARACTERISTICS

Four hundred and seventy three farmers (95\%) were men, 26 (5\%) women. The mean age was 52 , the youngest farmer being 27 years old and the oldest 88 . The mean number of years in farming was 31 , ranging from 2 years to 70 years. Three hundred and ninety four of the respondents $(79 \%)$ were farm owners, 97 $(19 \%)$ tenants, and nine $(2 \%)$ were farm managers. Most $(404 ; 81 \%)$ were married, 59 $(12 \%)$ were single, and $37(7 \%)$ were widowed, divorced, or separated.

Table 1 shows the distribution of farming types. Beef and sheep farming were predominant among the Welsh farmers, whereas arable farming was the most common English farm type. Nearly a third (32\%) ran only one type of farming operation, and over half (59\%) combined two or three different types of farming. The predominant types of single operation farm were arable $(54 ; 33 \%)$, dairy $(30 ; 19 \%)$, beef $(28 ; 17 \%)$, horticulture $(24 ; 15 \%)$, and sheep $(17 ; 11 \%)$. Farm size ranged from one acre to 4500 acres, with a mean of 300 acres (fig 1).

FINANCIAL PROBLEMS IN GENERAL

Over a quarter of the Welsh farmers and a fifth of the English farmers reported financial problems (table 2). In 31 of these cases ( $27 \%$ of those with financial problems) these problems were so severe that there was danger of losing the farm (a further 12 farmers without financial problems were in danger of losing their farms for other reasons). There were no significant associations between financial problems and farm type or farm size, although nearly a third $(10 / 32 ; 31 \%)$ of the farmers on very small farms ( $<20$ acres) had financial problems compared with under a fifth $(13 / 66$; $20 \%)$ of those on the largest farms $(>500$ acres).

Over three quarters $(81 \%)$ of the English farmers and more than two thirds $(72 \%)$ of the Welsh farmers were worried about money (table 2). Although a higher proportion of the Welsh farmers were not worried at all about financial matters, of the farmers who did worry about money, more Welsh (26\%) than English farmers $(14 \%)$ worried most of the time. Twenty two of the farmers who added comments to the questionnaire cited pressure from unsympathetic banks as an additional source of stress.

\section{FINANCIAL CONSEQUENCES OF RECENT}

LEGISLATION

When asked whether their financial situation had been affected by changes in agriculture policy or new legislation, more of the Welsh farmers reported that they had been adversely affected whereas a larger proportion of the English farmers indicated that the changes had been beneficial (table $2 ; \chi^{2}=8.91,2 \mathrm{df}$, $\mathrm{p}<0.02)$. This may reflect the fact that the changes favoured arable farmers, 45\% (100/ 221) of whom reported that they had benefited financially compared with $15 \%(40 / 264)$ of the non-arable farmers, although upland beef and sheep farmers were also eligible for subsidies. 


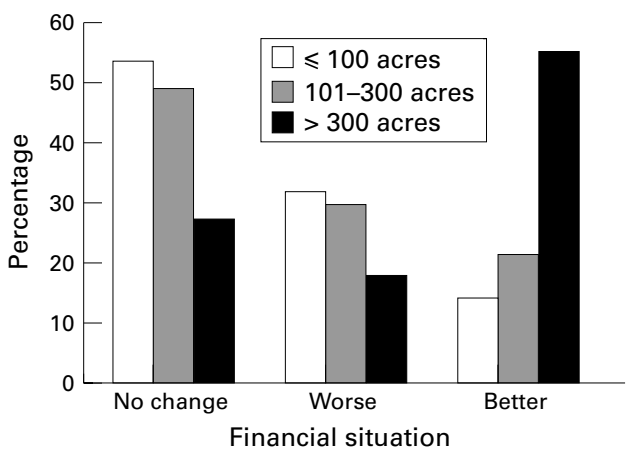

Figure 2 Effects of changes in agriculture policy and legislation on financial situation, by farm size.

Farm size was also associated with the financial changes resulting from the effects of legislation: of small farms $\leqslant 100$ acres and medium farms between 101 and 300 acres, about half had not experienced change compared with $28 \%$ of the large farms over 300 acres. When change was reported, small and medium-sized farms were more likely to be adversely affected $(32 \%$ and $30 \%$ ), whereas more of the large farms reported change for the better $(55 \%$, fig 2$)$.

OTHER CONSEQUENCES OF NEW LEGISLATION AND REGULATIONS

The effects of the changing legal and political framework within which British agriculture is required to operate were a source of stress for many of the farmers. Most were concerned about the amount of record keeping and paperwork involved $(304 / 492 ; 62 \%)$, and had difficulty understanding and completing the forms $(272 / 482 ; 56 \%)$. Just under half $(230 /$ $472 ; 49 \%)$ had experienced problems arising from the effects of new legislation or regulations. Those running mixed farms found all three aspects more stressful than farmers with single operations. Thus they had more problems with paperwork $(229 / 333,69 \%$ v 75/159, $47 \%$; relative risk $1.46,95 \%$ confidence interval $(95 \% \mathrm{CI}) 1.22$ to $1.74, \mathrm{p}<0.001)$, form completion $(194 / 325,60 \%$ v $78 / 157,50 \%$; relative risk $1.20,95 \%$ CI 1.00 to 1.44 , $\mathrm{p}<0.05)$ and the effects of changes in regulations $(170 / 320,53 \%$ v 60/152, $40 \%$; relative risk $1.35,95 \%$ CI 1.08-1.68, p<0.01).

Three hundred and six farmers added comments to the questionnaire indicating that the substantial increase in paperwork and regulations was a considerable source of worry. Much of the paperwork had to be done at busy times of the farming year, such as lambing or harvest, and smaller farmers were less able to employ experts to give them guidance. Frequent changes in decisions or interpretations of regulations made long term planning difficult and several farmers were anxious about incurring penalties for mistakes in completing the forms or failing to comply with obscure regulations. Thirty four of those who commented thought that the Common Agricultural Policy favoured their European counterparts, with cereal growers and fruit growers being especially disadvantaged. Thirty nine farmers mentioned the milk quota as a source of considerable stress, intro- ducing inflexibility and worries about overproduction.

Some of the added comments, however, drew attention to positive effects of the Common Agriculture Policy. About a fifth (62) of the 306 who mentioned problems, together with a further 42 farmers who had no problems, described ways in which they had benefited from the new regulations. Many were receiving arable area payments, setaside payments, or headage payments, although several suggested that relying on handouts was damaging to farmers' self esteem. For some the deregulation of the milk market and the introduction of milk quotas had produced a substantial increase in their income. Others had profited from the Integrated Administration and Control System (IACS) scheme and maintained that the paperwork and time this involved were worthwhile in view of the benefits which ensued.

ORGANOPHOSPHATE COMPOUNDS

Of the 217 sheep farmers in the study 127 $(59 \%)$ used organophosphate sheep dips. About a third $(68 / 207 ; 33 \%)$ had been drenched or soaked in organophosphate dips at some time, and $30(30 / 186 ; 16 \%)$ thought that their health had been affected by organophosphates. This group included 15 of the sheep farmers who had not been drenched. A further six farmers who did not keep sheep also thought that their health had suffered from exposure to organophosphate compounds used as seed dressings, crop sprays, or warble fly treatments. Two of these six farmers reported being drenched or soaked in the organophosphate compound. Symptoms mentioned included headaches, nausea, diarrhoea, sore throats, respiratory problems, joint pains and tingling in the hands and feet, low fertility, lethargy, memory loss, and depression. Thirteen of the farmers reporting symptoms attributed to organophosphate compounds had now stopped using them, but did not indicate if there was any subsequent change in their symptoms.

LONG HOURS

Seventy per cent of the farmers worked over 10 hours a day, including 20\% who worked over 15 hours. Working over 10 hours a day was most common for dairy farmers (146/167; $87 \%$ ), followed by beef farmers (198/266; $74 \%)$ and sheep farmers $(159 / 217 ; 73 \%)$. Those running single operations did not work such long hours as mixed farmers, $74 \%$ (251/338) of whom worked $>10$ hours a day compared with $61 \%(98 / 161)$ of those with only one farm type (relative risk $1.22,95 \%$ CI 1.06 to $1.40, \mathrm{p}<0.01$ ). The Welsh farmers were more likely than the English farmers to work over 10 hours a day $(91 / 113,81 \%$ v 256/383, $67 \%$; relative risk $1.20,95 \%$ CI 1.07 to 1.35 , $\mathrm{p}<0.01)$.

SOCIAL SUPPORT

Thirty one respondents drew attention to loneliness and social isolation as a possible cause of depression. However, most of the farmers in 
Table 3 Ill health by age group

\begin{tabular}{llc}
\hline & \multicolumn{2}{l}{$\begin{array}{l}\text { Health problems which interfered with } \\
\text { work }(n=489)\end{array}$} \\
\cline { 2 - 3 } Age group & $n$ & $\%$ \\
\hline$<35$ & 11 & 27.5 \\
$35-49$ & 44 & 27.0 \\
$50-64$ & 80 & 37.2 \\
$65>$ & 18 & 25.4 \\
Total & 153 & 31.3 \\
\hline
\end{tabular}

the survey $(457 / 495 ; 92 \%)$ had at least one person they could confide in, with $67 \%$ (328/490) having three or more close friends. Of those who did not live alone, 93\% (407/440) said that they could confide in the person with whom they lived. Over $70 \%$ had contact with other family members or friends at least once a week. Very few lived alone $(40 / 497 ; 8 \%)$.

HEALTH

Almost all the farmers (494/497; 99\%) were registered with a general practitioner. Twenty per cent of the farmers had seen their GP within the past month (92/456), and over half $(239 / 456 ; 52 \%)$ had been in contact within the past 6 months. Nearly a third $(155 / 495 ; 31 \%)$ had health problems which interfered with their work, including more than a quarter of those $<50$ years old (table 3 ). Seventy farmers described their health problems: of these the most common were back problems and arthritis.

OTHER COMMENTS AND SUGGESTIONS

As well as the comments already mentioned, other areas of concern for farmers were identified. Farmers' vulnerability to elements beyond their control-such as the weather, pests and diseases-was seen as a contribution to stress, as were changing social patterns, especially those involving the decline of rural amenities, the exodus of young people from the countryside, and the influx of urban newcomers who did not understand country ways. Some farmers felt increasingly beleaguered by the ill informed public perception of their position, exacerbated by irresponsible media and animal rights groups. Family problems and intergenerational conflict were cited as causes of stress, and several farmers emphasised the importance of an understanding wife. Attention was drawn to "farmer's nature"independent and proud, reluctant to share problems, conservative, and often resistant to fast changing technology. The fact that farmers' work and home life were inseparable made it more important for them to take holidays and develop interests outside the farm. The plight of small farmers with no leisure time was highlighted. Only six farmers mentioned bovine spongiform encephalopathy (BSE) as a potential source of stress, although as most of the questionnaires had been returned by March 1996, the full extent of the crisis was not yet apparent.

Various measures which might alleviate farmers' problems were suggested, including more government support for small farmers and protection for home grown produce, the establishment of farmers' cooperatives, and self help groups. It was suggested that farmers' unions could promote local social clubs for isolated farmers, take measures-for example, promotional videos - to give the public a more balanced view of British farming, provide a sympathetic banking service, and set up pension schemes to encourage older farmers to retire earlier and give more opportunities to young people.

\section{Discussion}

The survey response rate of over $50 \%$ was high (farming questionnaires usually elicit a return rate of $20 \%-25 \%{ }^{7}$ ). The low response from the FUW reflects the fact that we were unable to send non-responders a second copy of the questionnaire, and resulted in a relatively low overall response rate from Wales $(38 \%)$. Therefore the findings about Welsh farmers should be interpreted with some caution. The geographical distribution of respondents correlated highly with the agricultural census distribution figures. Although there was no difference in the geographical distribution of the responders and non-responders among the NFU members, we lacked other information with which to compare them. It should be noted that our survey was confined to members of the NFU and FUW, and that farmers with extreme financial and other difficulties might not be members of these organisations.

Most farmers in our survey worried about money, although not all of them had current financial problems. This is in keeping with previous findings from North America ${ }^{89}$ and the United Kingdom. ${ }^{7}{ }^{10} 11$ Our finding that small farms are more at risk may reflect the fact that these, together with farms which do not benefit from subsidies-such as horticultural and pig farms - may be more vulnerable to fluctuations in the market or financial climate, and to changes in agriculture policy. Since the time of the survey there have been considerable fluctuations in agricultural incomes, which fell by up to $37 \%$ in 1997 compared with $1996,{ }^{12}$ increasing financial problems for many farmers.

Financial support schemes arising from Britain's membership of the European Union and the Common Agricultural Policy have benefited some sections of the farming industry (notably arable farms, dairy farms, and upland beef and sheep farms), and also operate to control levels of production. However, the complicated forms and record keeping involved in qualifying for such subsidies cause considerable stress, as the rules and rates of payment vary from year to year, making forward planning extremely difficult, and there are severe penalties for inaccurate returns. Well over half the farmers in our study had problems in this area. Mixed farmers reported more difficulties than those running only one type of farm, which may be because of the more complex paperwork and record keeping involved in livestock farming.

In view of recent concern about organophosphate sheep dips, including possible effects of long-term exposure, ${ }^{13}$ it is noteworthy that 
about a third of the sheep farmers had been soaked by these dips. Although few of these thought that their health had been affected, 15 who had not been soaked reported symptoms which they attributed to organophosphate poisoning.

Working over 10 hours a day was common, especially for dairy and livestock farmers. If the agricultural workforce continues to decrease, those who remain in farming are likely to work even longer hours, with resultant detrimental effects on physical and mental health and family life.

Although social isolation is often considered a problem for farmers, very few of those in our survey were isolated. This finding confirms the low score given to isolation as a stressor in the study of McGregor et al. ${ }^{10}$ They thought that this might be explained because their survey population was farmers attending agricultural shows, and might represent those who were more likely to travel away from their farms. This explanation would not apply to our sample, who were randomly selected and returned questionnaires sent to their homes.

Nearly a third of the farmers had health problems which interfered with their work. Although more older farmers had health problems, it is notable that over a quarter of the farmers aged $<50$ also suffered from ill health. Illnesses - such as back problems or arthritiscan be especially difficult for farmers whose work involves much physical activity.

ACTION TO ALLEVIATE STRESS

As the problem of rural stress has become more apparent various measures have been undertaken to reduce it. Most counties have established rural initiatives to investigate and alleviate sources of stress. Several helplines, often run by farmers themselves, have been set up. Some of these have been very successful, whereas others have been discontinued because so few people used them. The Rural Stress Information Network was set up in 1996 at the Arthur Rank Centre, Stoneleigh Park, to coordinate information, best practice, and resources from the various local initiatives. The MAFF staff have been briefed to be aware of distress in farmers and to take a sympathetic approach to those who have difficulty with completion of forms.

Many of the initial problems about the legislation and regulations arising from Britain's membership of the European Union have now been overcome. In October $1996 \mathrm{MAFF}$ and the Welsh Office published the recommendations of an efficiency scrutiny team aimed at reducing the burden of paperwork. However, there is still a need for further simplification of the forms, assistance with their completion, and clear explanations of new regulations. Other practical measures which might be taken include retraining, housing and retirement schemes to help those who wish to leave farming, and greater flexibility of banks over financial loans. Farmers with small operations might benefit from cooperatives to provide machinery and labour.

This survey has confirmed findings from regional research studies that farmers are experiencing considerable stress, notably worries about finances, and difficulties arising from complex forms and regulations. Small farms and mixed farms are the most vulnerable, and policy makers should be particularly sensitive to the potential impact of new legislation on these groups. There is some evidence that farmers in Wales may also be particularly vulnerable. This study was part of a programme of research on suicide in
farmers conducted at Oxford University Department of Psychiatry with the support of the Department of Health for Psychiatry with the support of the Department of Health for
England and Wales. We thank the Reverand Nick Read, Director of the Rural Stress Information Network, Mr John Roach of the of the Rural Stress Information Network, Mr John Roach of the National Farmers' Union, and the Gloucestershire Farming
Friends for their advice; the National Farmers' Union and Friends for their advice; the National Farmers' Union and
Farmers' Union of Wales for their help with the distribution of the questionnaire; and all the farmers who took part in the study.

1 The problems in rural areas: a report of recommendations arising from an inquiry chaired by His Grace the Duke of Westminster DL. Leominster: Orphans Press, 1992.

2 Pauncefort Z. Communities at risk in Wiltshire. An overview of the county's problems and needs. Devizes: Wiltshire Commuthe county's problems and

3 Read N, ed. Rural stress: positive action in partnership. Report of a conference held on 21st March 1994 at the National Agricultural Centre Stoneleigh Park. Stoneleigh, Warwickshire: Royal Agricultural Society of England, 1994

4 Mayer N. North Humberside responding to rural stress. Hull: East Riding Health, 1995.

5 Charlton J, Kelly S, Dunnell K, et al. Suicide deaths in England and Wales: trends in factors associated with suicide deaths. Popul Trends 1993;71:34-42.

6 Ministry of Agriculture, Fisheries, and Food; The Scottish Office Agriculture and Fisheries Department; Department of Agriculture for Northern Ireland; Welsh Office. The digest of agricultural census statistics. United Kingdom 1994. London: HMSO, 1995.

7 Hatfield A. Evaluation of the North Yorkshire rural initiative (NYRI). Presented as poster at Health Alliance Awards, Tarch 1996.

8 Eberhardt BJ, Pooyan A. Development of the farm stress survey: factorial structure, reliability and validity. $E d u$ survey: factorial structure, reliability and validity.
cational Psychological Measurements 1990;50:393-402.

cational Psychological Measurements 1990;50:393-402.
9 Walker JL, Walker LJS. Self-reported stress symptoms in farmers. $\mathcal{F}$ Clin Psychol 1988;44:10-16.

10 McGregor M, Willcock J, Deary I. Farmer stress. Farm Management 1995;9:57-65.

11 Shaw S. Sources of stress in Upper Teesdale. Bishop Auckland: County Durham Health Authority, Dales Locality Team, 1997.

12 Ministry of Agriculture, Fisheries, and Food, Scottish Office Agriculture and Fisheries Department, Department of Agriculture for Northern Ireland, Welsh Office. Farm incomes in the United Kingdom 1996/97. London:TSO, 1998.

13 Stephens R, Spurgeon A, Calvert IA, et al. Neuropsychological effects of long-term exposure to organophosphates in sheep dip. Lancet 1995;345:1135-9.

14 Ministry of Agriculture, Fisheries, and Food/ Welsh Office Agriculture Department. Simplifying farmers' paperwork. The report of an efficiency scrutiny to reduce the burden of paperwork on farmers consistent with the need to protect human health, animal health and welfare, and the public purse. London: MAFF Publications, 1996. 
Appendix: The stress in farming questionnaire

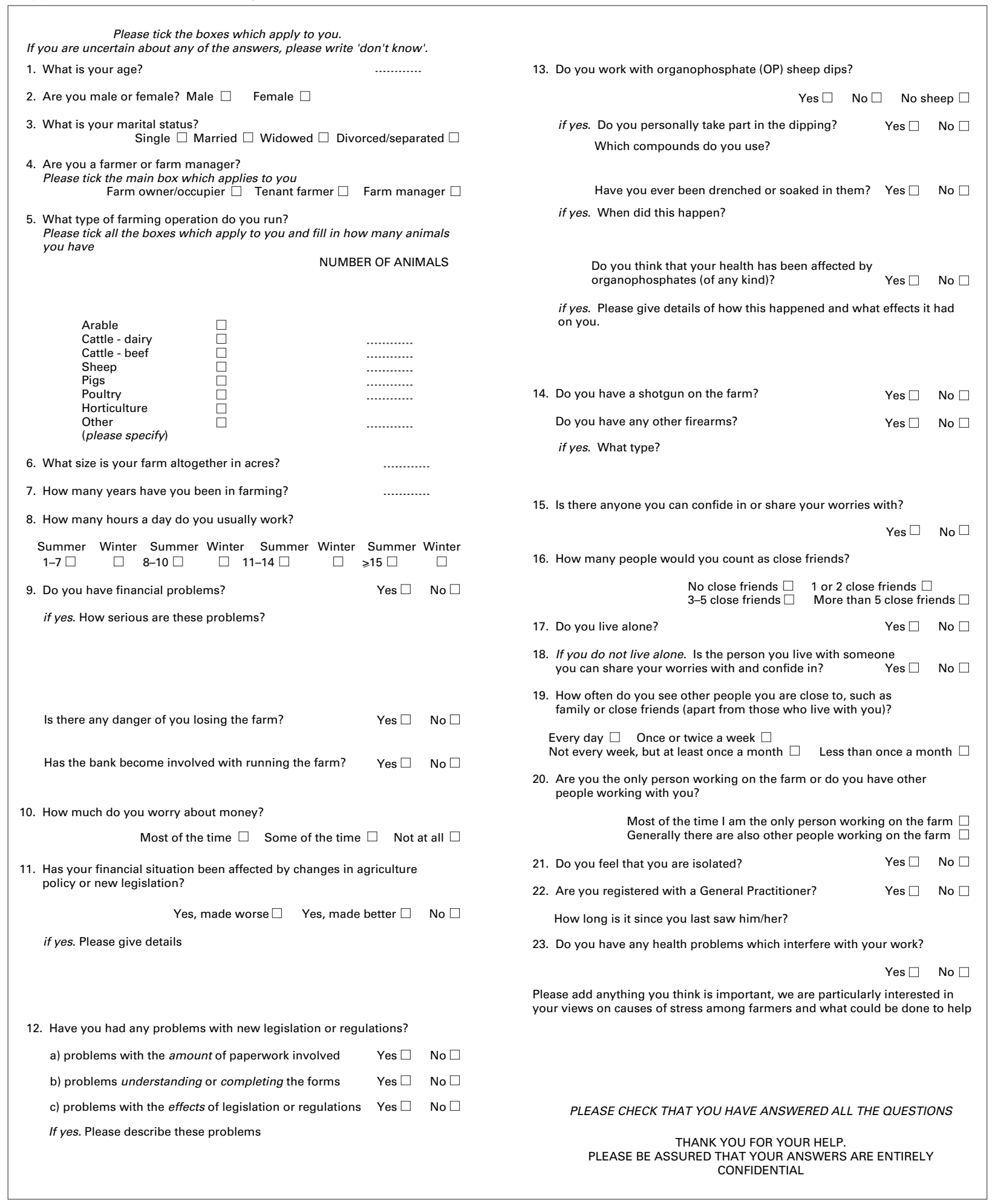

